\title{
Identification of the Single Channels that Underlie the N-Type and L-Type Calcium Currents in Bullfrog Sympathetic Neurons
}

\author{
Keith S. Elmslie \\ Department of Physiology, Tulane University Medical School, New Orleans, Louisiana 70112
}

\begin{abstract}
Most of the whole-cell calcium current of frog sympathetic neurons is an N-type current, blocked by $\omega$-conotoxin GVIA ( $\omega$ CGVIA). Thus, these cells should be an excellent system to study the properties of single $\mathrm{N}$-type channels. However, a channel that is active near $-10 \mathrm{mV}$ in isotonic $\mathrm{Ba}^{2+}$, originally identified as "N-type," corresponds more closely to a $\omega$ CGVIAresistant component of the whole-cell current observed in 100 $\mathrm{mm} \mathrm{Ba}^{2+}$. That conclusion would imply that the true singlechannel correlate of the macroscopic $\mathrm{N}$-current remains to be identified in frog sympathetic neurons. I report here recordings from cell-attached patches of a calcium channel that activates in the appropriate voltage range $\left(>0 \mathrm{mV}\right.$, in isotonic $\left.\mathrm{Ba}^{2+}\right)$ and is blocked by $\omega$ CGVIA. This channel has a slope conductance of $20 \mathrm{pS}$ (range, 17-25 pS) and a single-channel current of -1.3
\end{abstract}

$\mathrm{pA}$ at $0 \mathrm{mV}$. Other channels active in the same voltage range (24 pS, $-1.3 \mathrm{pA}$ at $0 \mathrm{mV}$ ) were identified as L-type channels because they exhibited long openings after repolarization in the presence of $1 \mu \mathrm{M}$ Bay K 8644 and were resistant to $\omega$ CGVIA. A third channel type (13-19 pS) was distinguished by current amplitude $(-0.6 \mathrm{pA}$ at $0 \mathrm{mV})$ and strong inactivation at $-40 \mathrm{mV}$. The similarity in slope conductance among these channels demonstrates that distinguishing them requires the consideration of additional properties. The $\omega$ CGVIA-sensitive channel can be identified as an $\mathrm{N}$-type calcium channel.

Key words: N-type calcium channels; L-type calcium channels; $\omega$-conotoxin GVIA; BayK 8644; sympathetic neurons; cellattached patch clamp
$\mathrm{N}$-type calcium current is important for many neuronal functions such as neurotransmitter release and controlling neuronal excitability. In frog sympathetic neurons, the calcium current recorded in $2 \mathrm{mM} \mathrm{Ba}^{2+}$ is primarily $\mathrm{N}$-type because $\sim 90 \%$ of the current is blocked by $\omega$-conotoxin GVIA ( $\omega$ CGVIA) (Jones and Jacobs, 1990; Elmslie et al., 1992). Therefore, these neurons should be an ideal preparation to study single $\mathrm{N}$-channels and have been used in previous studies (Lipscombe et al., 1989; Delcour and Tsien, 1993; Delcour et al., 1993). In these early studies, a channel was identified as "N-type," which was dihydropyridine (DHP)resistant and had properties that superficially match those of the whole-cell $\mathrm{N}$-current (e.g., activation near $-30 \mathrm{mV}$ and inactivation at a holding potential of $-40 \mathrm{mV}$ ). However, DHP resistance is a property shared by many calcium channel types. In addition, the single-channel and whole-cell data were not directly comparable because the recordings were made under different conditions, $110 \mathrm{mM} \mathrm{Ba}^{2+}$ versus $2 \mathrm{mM} \mathrm{Ba}{ }^{2+}$, respectively. More recent experiments have shown that changing the external $\mathrm{Ba}^{2+}$ concentration from 2 to $90 \mathrm{~mm}$ shifts the voltage-dependent activation of $\mathrm{N}$-current $\sim 40 \mathrm{mV}$ to the right (Elmslie et al., 1994). Thus, $\mathrm{N}$-channels activate near $+10 \mathrm{mV}$ in $100 \mathrm{~mm} \mathrm{Ba}^{2+}$. Voltagedependent inactivation was also shifted because $\mathrm{N}$-current was available from a holding potential of $-40 \mathrm{mV}$, which corresponds

Received Nov. 14, 1996; revised Jan. 29, 1997; accepted Jan 30, 1997.

This research was supported by National Institutes of Health Grant NS33671, the Louisiana Education Quality Support Fund (LEQSF-RD-A-28), and Pharmaceutical Research and Manufacturers of America Foundation. I thank Dr. Stephen W. Jones for suggesting the method for applying $\omega$-conotoxin to the isolated calcium channels and for his comments on an early version of this manuscript. In addition, I thank Dr. Geoffrey G. Schofield, Dr. Hye Kyung Lee, and Walter Robertson for helpful discussions and comments on this manuscript.

Correspondence should be addressed to Dr. Keith S. Elmslie, Department of Physiology, Tulane University Medical School, 1430 Tulane Avenue, New Orleans, LA 70112.

Copyright (C) 1997 Society for Neuroscience $\quad 0270-6474 / 97 / 172658-11 \$ 05.00 / 0$ to a holding potential of $-80 \mathrm{mV}$ in $2 \mathrm{~mm} \mathrm{Ba}^{2+}$. Unlike low-Ba ${ }^{2+}$ recordings, $\omega$ CGVIA block of N-current was completely reversible in $100 \mathrm{~mm} \mathrm{Ba}^{2+}$ (Boland et al., 1994; Elmslie et al., 1994).

The experiments in isotonic $\mathrm{Ba}^{2+}$ also revealed a previously unrecognized "novel" current, which was DHP- and $\omega$ CGVIAresistant (Elmslie et al., 1994; Zhou and Jones, 1995). Recently, single "novel" channels were shown to be similar to channels expressed in HEK 293 cells injected with E-class mRNA (Lewis et al., 1995). In addition, E-class mRNA has been identified in frog sympathetic neurons. Primarily to facilitate discussion, I have tentatively termed the "novel"-channel $E_{f}$ for frog E-class channel.

Surprisingly, $\mathrm{E}_{\mathrm{f}}$-channels showed characteristics similar to the putative N-channel previously identified by Tsien and colleagues (Lipscombe et al., 1989; Delcour et al., 1993). Both channels activate near $-30 \mathrm{mV}$, are strongly inactivated at a holding potential of $-40 \mathrm{mV}$, have a slope conductance of $\sim 19 \mathrm{pS}$, and have a current amplitude at $0 \mathrm{mV}$ of approximately $-0.6 \mathrm{pA}$. These similarities lead us to conclude that the two channels were the same (Elmslie et al., 1994). If this were true, the $\omega$ CGVIAsensitive $\mathrm{N}$-channel in frog sympathetic neurons remained to be identified. I report here a calcium channel that activates near +10 $\mathrm{mV}$ and is reversibly blocked by $\omega$ CGVIA. This channel resembles some putative N-channels (Plummer et al., 1989; Mathie et al., 1992; Rittenhouse and Hess, 1994; Carabelli et al., 1996) but differs from others, including the first putative N-channels (Nowycky et al., 1985; Fox et al., 1987) and those previously reported from frog sympathetic neurons (Lipscombe et al., 1989; Delcour and Tsien, 1993; Delcour et al., 1993).

\section{MATERIALS AND METHODS}

Cells. Neurons were dissociated from caudal paravertebral sympathetic ganglia of adult bullfrogs (Rana catesbeiana) by a collagenase/dispase digestion and trituration (Kuffler and Sejnowski, 1983; Jones, 1987; 
Elmslie, 1992). Cells were maintained in L-15 culture medium, supplemented with $10 \%$ fetal bovine serum and penicillin/streptomycin, at $4^{\circ} \mathrm{C}$ until use (usually 1-14 d).

Cell-attached patch recording. The pipette solution consisted of (in mM) $100 \mathrm{BaCl}_{2}, 10$ tetraethylammonium (TEA) chloride, 5, 4-aminopyridine (4-AP), and $10 N$-methyl-D-glucamine (NMG)-HEPES, pH 7.2. The TEA and 4-AP were required to suppress $\mathrm{K}^{+}$currents because intracellular $\mathrm{K}^{+}$ was not replaced. Gigaseals were formed in an extracellular solution designed to zero the cell's membrane potential. This zeroing solution contained (in mM) $100 \mathrm{KCl}, 10 \mathrm{~K}$-HEPES, and 5 NMG-EGTA, pH 7.2. In a few experiments $(n=5)$, cell-attached macropatches were excised to demonstrate that the cells do not maintain a membrane potential in the high- $\mathrm{K}^{+}$solution. Voltage ramps $(1 \mathrm{mV} / \mathrm{msec})$ were used to monitor the macroscopic $I-V$ before and after excision. Although the calcium channel current rundown was rapid after excision, peak current did not move along the voltage axis, indicating that the membrane potential and bath potential were equal (data not shown). Unless noted otherwise, the zeroing solution contained the L-channel agonist $( \pm)$ Bay K $8644(1 \mu \mathrm{M})$ to reveal the presence of L-channels in the patch (Plummer et al., 1989).

Electrodes for single-channel experiments were fabricated from Corning 7052 glass (OD $1.5 \mathrm{~mm}$, ID $0.86 \mathrm{~mm}$; A-M Systems, Everett, WA) and had resistances of 3-15 M $\Omega$. The electrodes were coated with the General Electric equivalent of SYLGARD (GE Silicones RTV615, General Electric Company, Waterford, NY). The small tip size made filling the electrode difficult. Therefore, recordings were done using fiber-filled glass to facilitate filling the electrode without compromising seal formation. Non-fiber-filled glass was used for the $\omega$ CGVIA experiments, in which the tip-filling and back-filling solutions were different (see below).

Data acquisition. Calcium-channel currents were recorded using an Axopatch 200A amplifier (Axon Instruments, Foster City, CA). The experiment was controlled by a Macintosh II computer (Apple Computer, Cupertino, CA) running S3 data acquisition software written by Dr. Stephen Ikeda (Guthrie Research Institute, Sayre, PA). Currents were digitized with a MacAdios II analog-digital converter (GW Instruments, Somerville, MA) and stored on a $170 \mathrm{MB}$ hard disk.

Currents were filtered at $2 \mathrm{kHz}$ with the 4-pole Bessel filter on the Axopatch 200A and amplified an additional $10 \times$ with a Frequency Devices 900 Bessel filter (Frequency Devices, Haverhill, MA) before being digitized at $10 \mathrm{kHz}$ ( 5 times the filter cutoff frequency). Data were analyzed using IgorPro (WaveMetrics, Lake Oswego, OR) and Excel (Microsoft, Redmond, WA) run on a Quadra 800 microcomputer (Apple Computer).

Data were obtained in sets of 100 voltage steps of $100 \mathrm{msec}$ duration delivered at a $2 \mathrm{sec}$ interval $(\sim 3.5 \mathrm{~min} /$ data set). The test voltage was varied randomly across data sets to compensate for drifts in open probability $\left(P_{\mathrm{o}}\right)$ during the recording. During the 100 sweep data sets, the noise level would sometimes briefly increase. These brief noise events tended to occur more frequently as the recording time increased. Sweeps recorded during these noise events were excluded from analysis.

Analysis of single-channel records. Uncorrected capacitative current and voltage-independent leakage current were removed from the records by averaging sweeps without channel openings (nulls) and subtracting this from active sweeps. This procedure was done within a single data set (typically 100 sweeps) to decrease the possible effect of changes in leakage currents or capacitative currents over time. If null sweeps were rare or absent, a null record was made by fitting the null regions of low activity sweeps with the sum of exponentials to obtain a line that closely approximated the capacitative and leakage currents. When generating pseudomacroscopic currents for comparison within a patch, active sweeps for each current were subtracted using a leakage record averaged from an equal number of null sweeps. This was done to ensure similar noise levels in each of the pseudomacroscopic currents (see Figs. 1-3, 5-7).

Low-variance histograms. Because of the brief open times exhibited by the calcium channels at some voltages, the use of all-points histograms has been avoided. Instead, low-variance analysis has been used to estimate single-channel current levels because it excludes points from regions of high variance (e.g., channel opening or closing transitions) (Patlak, 1988, 1993; Elmslie et al., 1994). Briefly, the mean current amplitude and variance were calculated for a window (generally 5-20 points; $0.5-2 \mathrm{msec}$ ) advanced across the record in 1 point increments. If the variance in the window was $\leq$ baseline variance, the mean current amplitude was kept for the histogram. The histogram binwidth was $0.05 \mathrm{pA}$. The $y$-axis of the histogram was log-transformed to truncate large peaks relative to small peaks.

$\omega C G V I A$ application. Single-channel data were recorded while the concentration of $\omega$ CGVIA at the patch was altered with a technique analogous to that used for introducing nystatin to the membrane in perforated-patch recordings (Horn and Marty, 1988). The electrode tip was filled with one solution (e.g., toxin-free), and the electrode was back-filled with another (e.g., toxin-containing pipette solution). The patch concentration of a test substance could be increased or decreased by switching tip-filling and back-filling solutions. Time was zeroed when the bubble separating the two solutions was tapped out to allow the solutions to mix. The amount of solution in the tip was measured before the electrode was back-filled. On average, $1.3 \mathrm{~mm}$ of the tip was filled (range, $0.93-2.1 \mathrm{~mm}$ ) and strong positive pressure was maintained on the pipette until cell contact was made. In general, less solution was used when $100 \mu \mathrm{M} \omega \mathrm{CGVIA}$ was in the tip solution because $\omega$ CGVIA dissociation is slow in $100 \mathrm{~mm} \mathrm{Ba}^{2+}$ (Boland et al., 1994; Elmslie et al., 1994). Filling the tip with $100 \mu \mathrm{M} \omega \mathrm{CGVIA}$ did not compromise seal formation. These experiments used only nonfilament electrode glass so that the two solutions would not mix until the bubble was tapped out.

Drugs. ( \pm )-Bay K 8644 was obtained from Research Biochemicals (Natick, MA). $\omega$ CGVIA was obtained from either LC laboratories (Woburn, MA) or Bachem Bioscience (King of Prussia, PA). TEA, 4-AP, EGTA, and HEPES were obtained from Sigma (St. Louis, MO). All other chemicals were reagent grade.

\section{RESULTS}

The goal of this work was to identify the single calcium channel that generates macroscopic N-current. Therefore, a majority of recordings were done from a holding potential of $-40 \mathrm{mV}$, where $\mathrm{E}_{\mathrm{f}}$-channels are primarily inactivated (Elmslie et al., 1994). $\mathrm{N}$-channels in $100 \mathrm{~mm} \mathrm{Ba}^{2+}$ are active from a holding potential of $-40 \mathrm{mV}$, which is equivalent to $-80 \mathrm{mV}$ in $2 \mathrm{mM} \mathrm{Ba}^{2+}$ (Elmslie et al., 1994). Bay K 8644 (1 $\mu \mathrm{M})$ was bath-applied to all patches to help separate N-channels from L-channels. Bay K 8644 increases the open time of L-channel gating both during voltage steps and on repolarization to the holding potential (tail openings). The presence of these tail openings was used to tentatively identify L-channels (Plummer et al., 1989). As will be seen, the presence of these tail openings correlates very well with other properties expected for L-channels such as activation at voltages more than $-30 \mathrm{mV}$ and resistance to block by $\omega$ CGVIA.

\section{General description of recorded channels}

\section{Putative N-channels}

Our whole-cell recordings in $100 \mathrm{mM} \mathrm{Ba}^{2+}$ showed that $\mathrm{N}$-channels should activate at voltages $>0 \mathrm{mV}$, and peak macroscopic current should occur between +25 and $+40 \mathrm{mV}$ (Elmslie et al., 1994). In addition, N-channels should deactivate rapidly at $-40 \mathrm{mV}$ in the presence of Bay K 8644 (i.e., no long tail openings). One type of calcium channel available from a holding potential of $-40 \mathrm{mV}$ matched these properties (Fig. 1). Activity of these channels was measured in isolation from other channel activity in nine patches (not exposed to $\omega$ CGVIA). Channel gating was observed during voltage steps ranging from 0 to $+50 \mathrm{mV}$ with the open probability $\left(P_{\mathrm{o}}\right)$ increasing with voltage. For the example illustrated in Figure 1, $P_{\mathrm{o}}$ increased from 0.02 at $0 \mathrm{mV}$ to 0.54 at $+30 \mathrm{mV}$. (The highest voltage at which $P_{\mathrm{o}}$ could be accurately measured in this patch.) The slope conductance was calculated from 0 to $+40 \mathrm{mV}$ by linear regression and was found to be $21 \mathrm{pS}$ with a single-channel current at $0 \mathrm{mV}$ of $-1.3 \mathrm{pA}$ ( 9 patches not exposed to $\omega$ CGVIA; Figs. $1 D, 4 A$ ). Consistent with whole-cell data, ramp currents showed measurable inward current at voltages greater than or equal to $+10 \mathrm{mV}$, and the mean voltage generating peak current was $+35 \mathrm{mV}$ for the five patches examined in this data set (range +28 to $+41 \mathrm{mV}$; Fig. $1 C$ ). Voltage ramps were not recorded for the other four patches (not exposed to $\omega$ CGVIA). Channel activity showed no inactivation during 100 msec steps to $+20 \mathrm{mV}$ (Figs. $1 A, 5 A, 6 A$ ). However, a small 
A

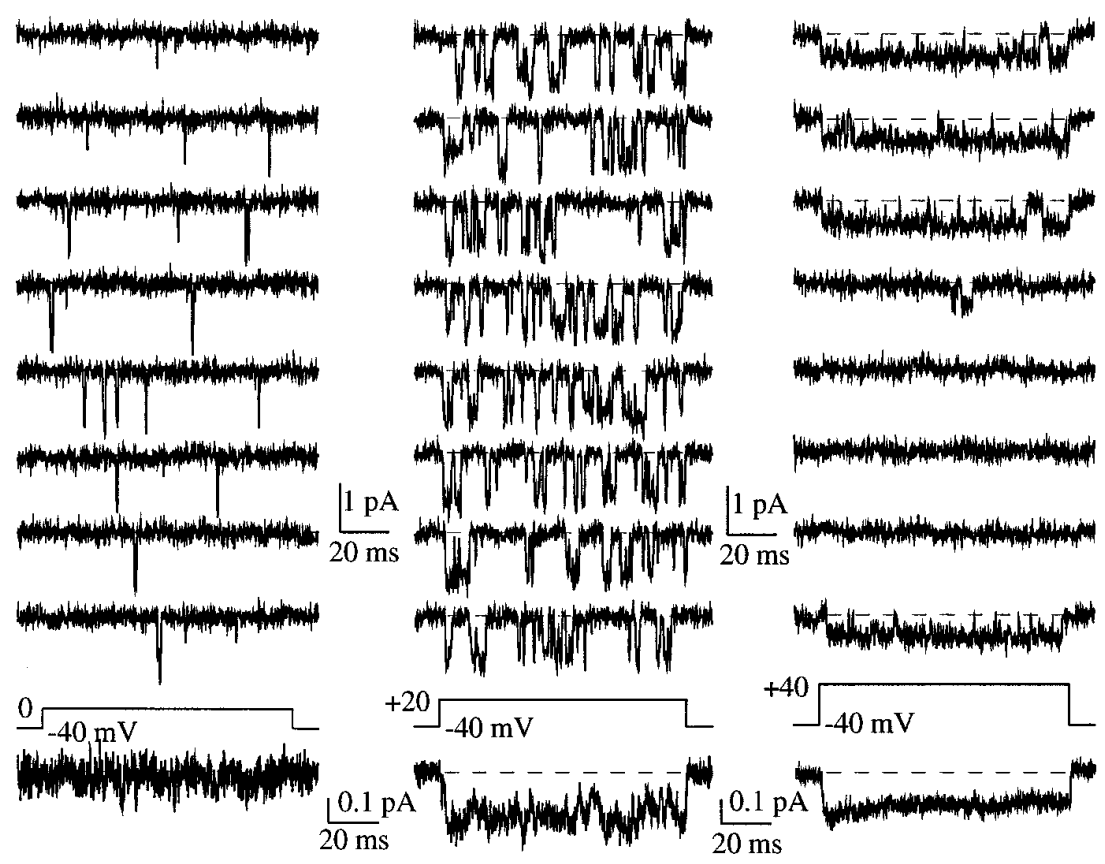

B

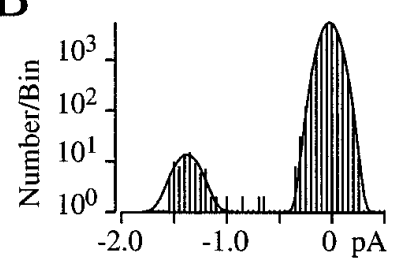

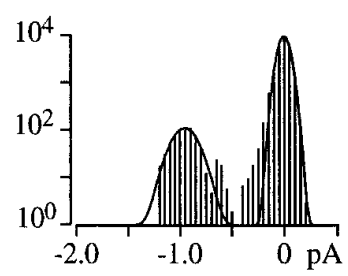

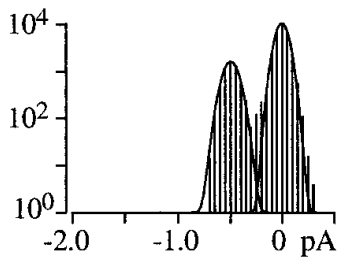

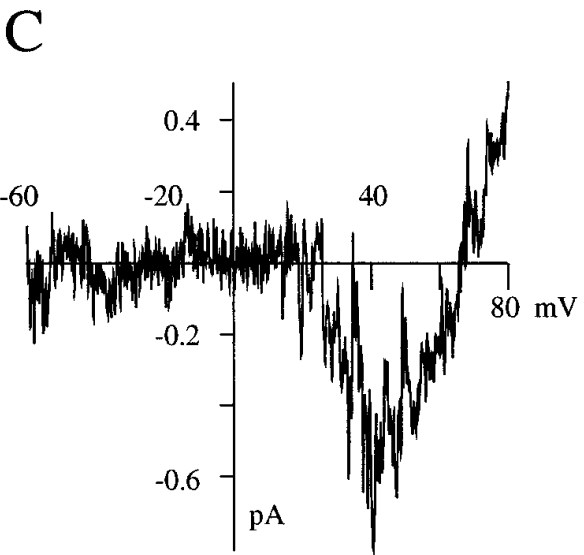

$\mathrm{D}$

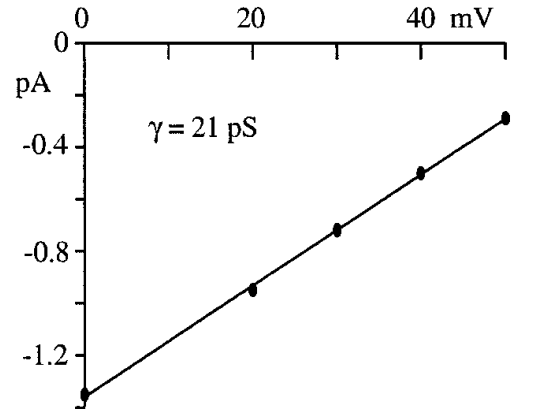

Figure 1. Putative N-type calcium channel. A, Eight consecutive single-channel records are shown for three voltages, along with the pseudomacroscopic current for each voltage. This patch contained a single putative $\mathrm{N}$-channel and an $\mathrm{E}_{\mathrm{f}}$-channel, which was occasionally active during steps from the holding potential of $-40 \mathrm{mV}$. The number of sweeps averaged for the pseudomacroscopic currents were 34,70 , and $100 \mathrm{for} 0 \mathrm{mV},+20 \mathrm{mV}$, and $+40 \mathrm{mV}$, respectively. The interval between sweeps was $2 \mathrm{sec}$, and the illustrated records were Gaussian-filtered at $1 \mathrm{kHz}$. This patch was not exposed to Bay K 8644 until after these data were taken. Note the apparent substate visible in the second sweep from the top in the $+20 \mathrm{mV}$ steps and in the low-variance histogram for $+20 \mathrm{mV}$ (peak $\sim-0.6 \mathrm{pA}$ ). This was the only patch where such a sublevel was observed. $B$, Low-variance-mean current histograms are shown for each of the three voltage steps in $A$. The window size was 3 points for $0 \mathrm{mV}$ and 10 points for both +20 and $+40 \mathrm{mV}$. The binwidth was 0.05 $\mathrm{pA}$. The smooth lines are single Gaussian fits. Note that the $\mathrm{E}_{\mathrm{f}}$-channel is evident as a shoulder on the zero peak in the $+20 \mathrm{mV}$ histogram. $C$, Current-voltage $(I-V)$ relation averaged from five sweeps where voltage was ramped from -80 to $+80 \mathrm{mV}$ over $160 \mathrm{msec}(1 \mathrm{mV} / \mathrm{msec})$. $D$, The single-channel current amplitude taken from the low-variance-mean histograms was plotted against the step potential. A linear regression fit to all of the points yields a slope conductance of $21 \mathrm{pS}$ and a $0 \mathrm{mV}$ intercept of $-1.38 \mathrm{pA}$. All data are from the same patch.

inactivating component could be observed in the pseudomacroscopic records for steps to $+40 \mathrm{mV}$ (Figs. $1 A$ ). This incomplete inactivation is consistent with whole-cell N-current data (Jones and Marks, 1989; Werz et al., 1993). The density of these channels was high because only two of nine patches (not exposed to $\omega$ CGVIA) appeared to contain a single N-channel.

The current level of one channel in this group [shown as (double triangle) in Fig. $4 A$ ] was larger than the others. The slope conductance of this channel was $20 \mathrm{pS}$, like the other channels, but the current amplitude at $+20 \mathrm{mV}$ was $-1.16 \mathrm{pA}$ compared wiith a mean of $-0.85 \mathrm{pA}(n=8$; range -0.74 to $-0.95 \mathrm{pA})$ for the others. It is possible that this is a different channel type. Alternatively, it could be the same channel type gating in a mode with a larger single-channel current as described for the $\mathrm{N}$-channel in rat sympathetic neurons (Plummer et al., 1989; Rittenhouse and Hess, 1994). Mode switching was not observed. However, it could have been missed because I recorded from only two single-Nchannel patches.

\section{L-channels}

A separate population of channels could be distinguished by long tail openings in the presence of the DHP agonist Bay K 8644 and activation near $-20 \mathrm{mV}$ (compared with $+10 \mathrm{mV}$ for the putative $\mathrm{N}$-channel; Fig. 2). The mean voltage for peak of the pseudomacroscopic ramp current was $+23 \mathrm{mV}$ (range +12 to $+38 \mathrm{mV}, n=$ 9; Fig. 2C). Single L-channel patches (4/10) were more frequently encountered compared with $\mathrm{N}$-channels $(2 / 9)$ and $\mathrm{E}_{\mathrm{f}}$-channels (0/5; see below). Although $\mathrm{N}$ - and L-channels were easily distinguished by activation voltage, the single-channel current and slope conductance were found to be similar between these channels (Fig. 4). The L-channel current at $+20 \mathrm{mV}$ ranged from -0.62 to $-0.98 \mathrm{pA}$ (mean $-0.81 \mathrm{pA}$ for 8 patches), which overlaps with the putative $\mathrm{N}$-channel (mean $-0.87 \mathrm{pA}$; see above). The singlechannel conductance measured from -40 to $+20 \mathrm{mV}$ was $24 \mathrm{pS}$ (Fig. $4 B$ ). L-channels show a large variability in both the singlechannel conductance (range 19-33 pS) and the current amplitude at $0 \mathrm{mV}$ (range 1.0-1.4 pA). One explanation for this variability is 
A
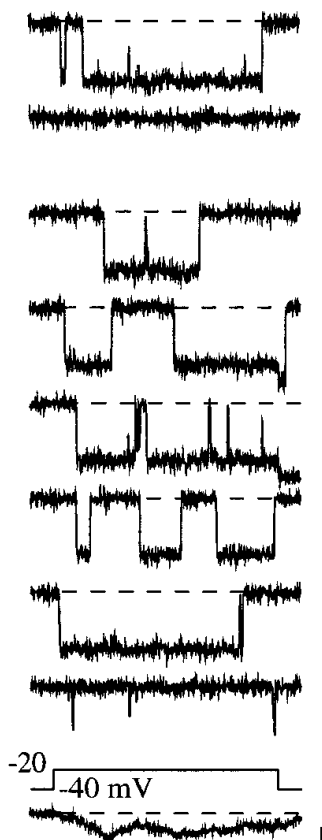

B

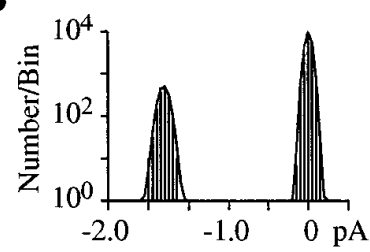

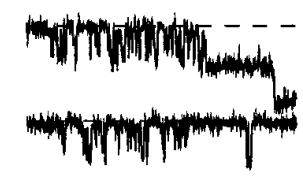
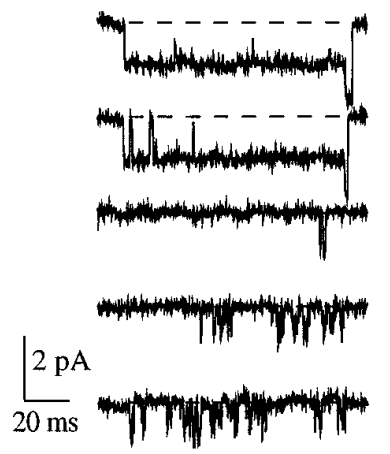

$\frac{2 \mathrm{pA}}{20 \mathrm{~ms}}$

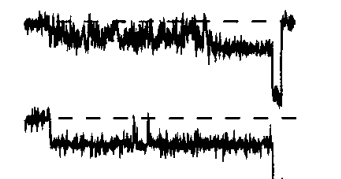

C

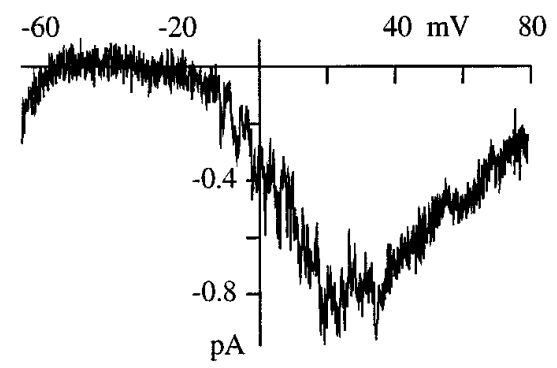

$\mathrm{D}$

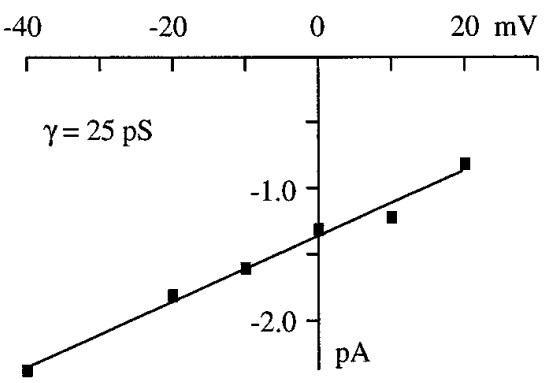

Figure 2. L-channel recorded in the presence of $1 \mu \mathrm{M}$ BayK 8644. A, Eight consecutive sweeps are shown for each of three voltages. The pseudomacroscopic currents are averages of 59, 100, and 100 sweeps for $-20,0$, and $+20 \mathrm{mV}$, respectively. Note the long tail openings at $-40 \mathrm{mV}$ and the slow tail current in the pseudomacroscopic currents. The illustrated single-channel sweeps were Gaussian-filtered at $1 \mathrm{kHz}$, and two L-channels were present in the patch. $B$, Low-variance-mean histograms were generated with a window size of 5 points for $-20 \mathrm{mV}$ and 10 points for both 0 and $+20 \mathrm{mV}$. The smooth lines are single Gaussian fits. $C$, The ramp $I-V$ was averaged from 15 voltage ramps $(1 \mathrm{mV} / \mathrm{msec})$ given with an interval of $2 \mathrm{sec}$. The holding potential for the ramps was $-40 \mathrm{mV}$. $D$, The single-channel current amplitude taken from the low-variance-mean histograms was plotted against the step potential. A linear regression fit to all of the points yields a slope conductance of $25 \mathrm{pS}$ and a $0 \mathrm{mV}$ intercept of $-1.31 \mathrm{pA}$. All data are from the same patch.

that frog sympathetic neurons express multiple L-channel types as shown previously for rat cerebellar granule cells and rat hypocampal pyramidal cells (Forti and Pietrobon, 1993; Kavalali and Plummer, 1994).

\section{$E_{f}$-channels}

$\mathrm{E}_{\mathrm{f}}$-channel activity was observed during many of the $\mathrm{N}$ - and L-channel recordings (12/28), although the holding potential was $-40 \mathrm{mV}$. The pattern of gating was brief periods of activity separated by long periods of inactivation. This is expected because whole-cell $\mathrm{E}_{\mathrm{f}}$-current is $\sim 80 \%$ inactivated at $-40 \mathrm{mV}$ (Elmslie et al., 1994). N- or L-channel activity was absent in five additional patches, allowing the holding potential to be set to $-80 \mathrm{mV}$ (total patches with $\mathrm{E}_{\mathrm{f}}$-channels 17/43; Table 1, rows 1 and 2). Each of these five patches contained at least two $\mathrm{E}_{\mathrm{f}}$-channels.

Activity of $\mathrm{E}_{\mathrm{f}}$-channels could be recorded during steps to -40 $\mathrm{mV}$ (holding potential $-80 \mathrm{mV}$ ). However, measurable inward current during voltage ramps was not apparent until approximately $-20 \mathrm{mV}$ (Fig. $3 A, C$ ). The voltage generating peak inward current was measured from voltage ramps to be $+20 \mathrm{mV}$ (range 13-27 $\mathrm{mV} ; n=3$ ), which is similar to whole-cell $\mathrm{E}_{\mathrm{f}}$-current (Elmslie et al., 1994). The slope conductance measured by regres-
Table 1. Number of patches containing the different calcium channel types

\begin{tabular}{lllccl} 
& N-Type & L-Type & $\begin{array}{c}\mathrm{E}_{\mathrm{f}}- \\
\text { Type }\end{array}$ & No Activity & Total \\
\hline Control & 9 & 4 & 6 & 6 & 21 \\
$\omega$ CGVIA-diffusion & 9 & 6 & 11 & 3 & 22 \\
Constant $\omega$ CGVIA & 1 & 7 & 5 & 10 & 20
\end{tabular}

The frequency of N-channel patches is reduced by $\omega$ CGVIA. The number of patches containing one of three channel types or no measurable channel activity is shown for three treatments. The total number of patches is less than the sum of the other 4 columns because $\mathrm{E}_{\mathrm{f}}$-channels were often observed along with $\mathrm{N}$ - or L-channels (see text). $\omega$ CGVIA-diffusion includes patches recorded during both $\omega$ CGVIA-diffusion to the patch and $\omega$ CGVIA-dilution from the patch. For the constant $\omega$ CGVIA treatment, the pipet solution contained $100 \mu \mathrm{M} \omega \mathrm{CGVIA}$.

sion fit ranged from 13 to $20 \mathrm{pS}$ in 12 patches (with and without $\omega$ CGVIA in the pipette; mean $16 \mathrm{pS}$ ) with a mean current amplitude at $0 \mathrm{mV}$ of $-0.6 \mathrm{pA}$ (range -0.4 to $-0.7 \mathrm{pA}$; Fig. $4 A$ ). The conductance values are in the range previously reported for these channels (15-16 pS: Lipscombe et al., 1988, 1989; 18 pS: Delcour et al., 1993; 19 pS: Elmslie et al., 1994). The variability in 

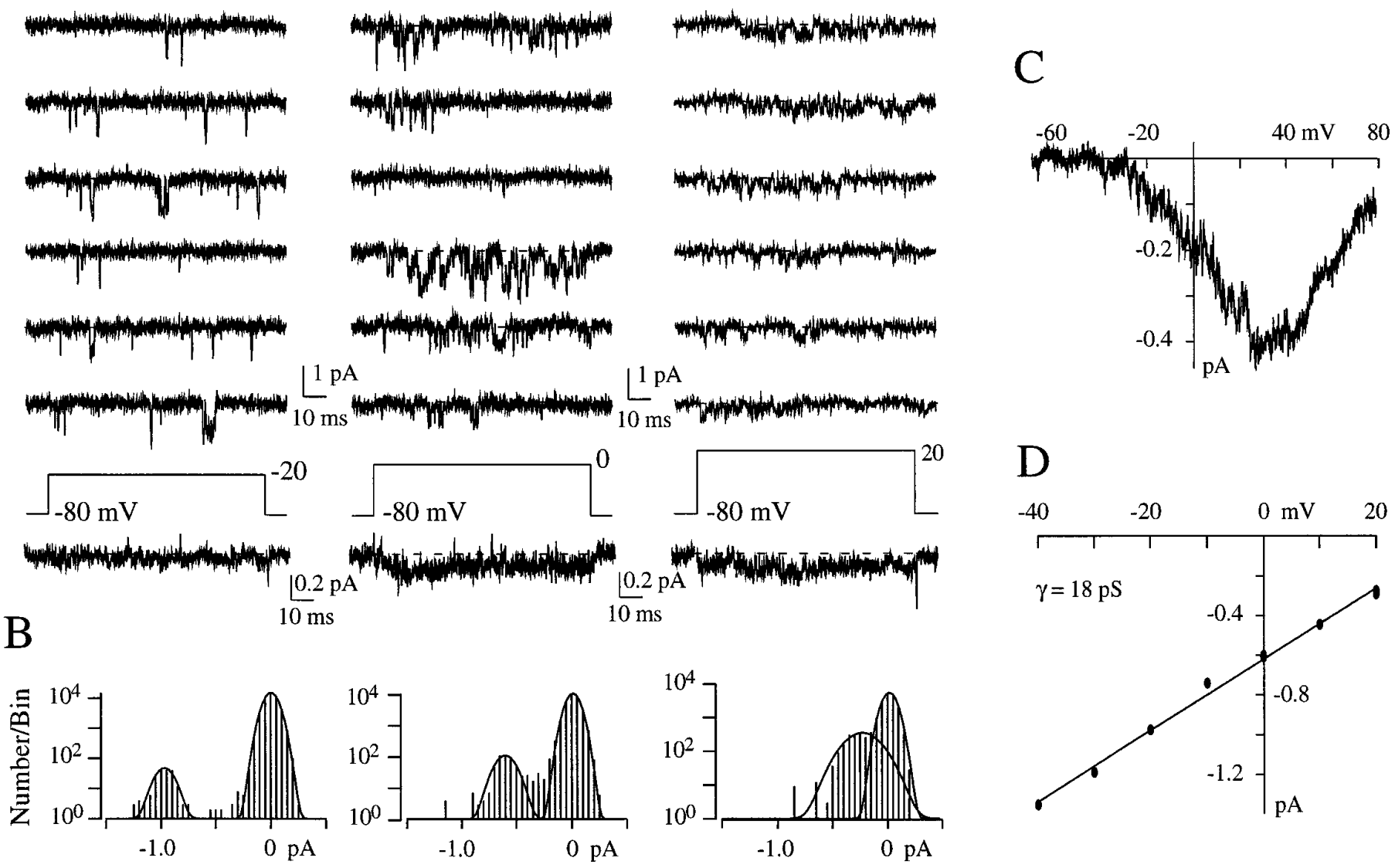

$10 \mathrm{~ms}$
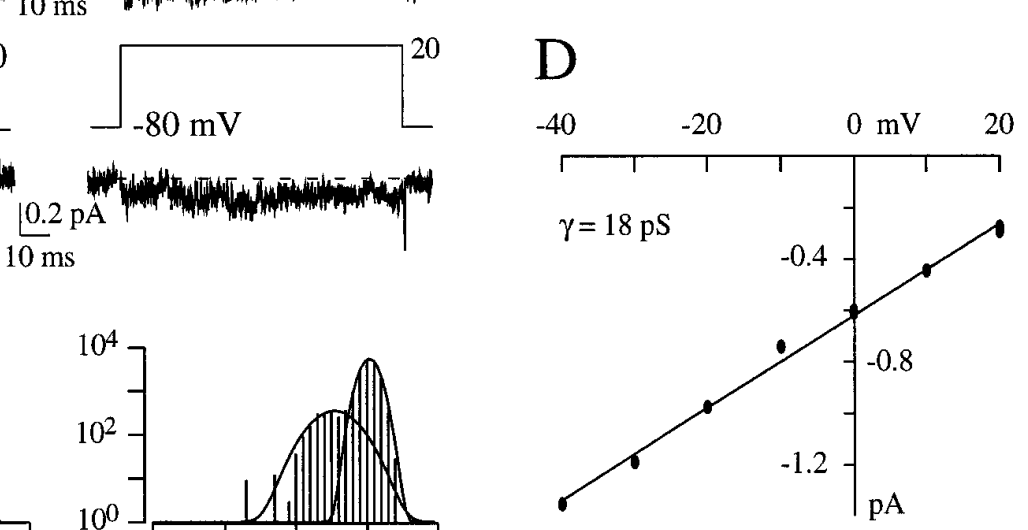

Figure 3. $\mathrm{E}_{\mathrm{f}}$-channel activity recorded in the presence of $\omega$ CGVIA. $A$, Eight consecutive records are shown for each of three voltages. Note that the holding potential was $-80 \mathrm{mV}$. The pipette was front-filled with the standard pipette solution, but back-filled with that solution containing $100 \mu \mathrm{M}$ $\omega$ CGVIA (see $\omega$ CGVIA application in Materials and Methods). The pseudomacroscopic currents are averages of 83, 90, and 51 sweeps for $-20,0$, and $+20 \mathrm{mV}$, respectively. This patch contained at least three $\mathrm{E}_{\mathrm{f}}$-channels. $B$, Low-variance-mean histograms were generated using windows sizes of 10 points for -20 and $0 \mathrm{mV}$ and 15 points for $+20 \mathrm{mV}$. C, Pseudomacroscopic current was averaged from 70 voltage ramps $(1 \mathrm{mV} / \mathrm{msec})$ given with an interval of $2 \mathrm{sec} . D$, Single-channel current amplitude was plotted against the step potential. A linear regression to all of the points from -40 to $0 \mathrm{mV}$ gave a slope conductance of $18 \mathrm{pS}$ and a current amplitude at $0 \mathrm{mV}$ of $-0.6 \mathrm{pA}$. All data are from the same patch.

slope conductance may reflect multiple channel types, subconductance states, and/or different gating modes. The absence of single$\mathrm{E}_{\mathrm{f}}$-channel patches in the present study prevents distinguishing among these possibilities.

\section{Frequency of channel observation}

Putative N-channels were observed in 18 of 43 patches (Table 1, rows 1 and 2; excluding patches continuously exposed to $\omega$ CGVIA; see below). This frequency is consistent with the wholecell calcium current recorded in $100 \mathrm{~mm} \mathrm{Ba}^{2+}$, which is $50-70 \%$ N-current (Elmslie et al., 1994). L-channels were observed less frequently than $\mathrm{N}$-channels (10/43 patches; Table 1 , rows 1 and 2$)$ but more frequently than expected from whole-cell recording, in which L-current comprises $\sim 5 \%$ of the total calcium current. The frequency of observing $E_{\mathrm{f}}$-channels was similar to that of $\mathrm{N}$-channels (17/43; Table 1, rows 1 and 2). The large number of patches with $\mathrm{E}_{\mathrm{f}}$-channels was expected because $\mathrm{E}_{\mathrm{f}}$-current comprises 30-50\% of the whole-cell current recorded in isotonic $\mathrm{Ba}^{2+}$ (Elmslie et al., 1994).

\section{Identification of $\mathrm{N}$-channels by sensitivity to $\omega \mathrm{CGVIA}$}

The $20 \mathrm{pS}$ calcium channel is the best candidate to be the N-type calcium channel because it is active over the voltage range ex- pected for $\mathrm{N}$-current in $100 \mathrm{~mm} \mathrm{Ba}^{2+}$. To test this hypothesis, $\omega$ CGVIA was applied during cell-attached patch recordings of single calcium channels. This was accomplished by filling the electrode tip with toxin-free solution and back-filling with the pipette solution containing $100 \mu \mathrm{M} \omega \mathrm{CGVIA}$. The high concentration of $\omega$ CGVIA was required to ensure block in isotonic $\mathrm{Ba}^{2+}$ (Boland et al., 1994). Figure $5 A$ shows the blocking effect of $\omega$ CGVIA on putative N-channels in one experiment. This channel had a slope conductance of $22 \mathrm{pS}$, and the single-channel current is plotted as a filled square in Figure $6 C$. The pseudomacroscopic current averaged from 15 voltage ramps showed activation near $+10 \mathrm{mV}$ and peak at $+44 \mathrm{mV}$ (Fig. $5 C$ ). The time course of the block was measured from pseudomacroscopic step currents. Figure $5 B$ shows the time course of the $\omega$ CGVIA effect in six patches that contained putative N-channels. In five of six patches, channel activity decreased with time, as expected for increasing concentration of $\omega$ CGVIA at the patch. $\mathrm{E}_{\mathrm{f}}$-channel activity was noticed in four of the five $\mathrm{N}$-channel patches. However, the activity periods were short (holding potential $-40 \mathrm{mV}$ ) and the small current amplitude made identification easy (see Fig. 6). One of the $\mathrm{N}$-channel patches contained an L-channel in addition to an $\mathrm{E}_{\mathrm{f}}$-channel. The single L-channel current was smaller $(-0.7 \mathrm{vs}$ 
A

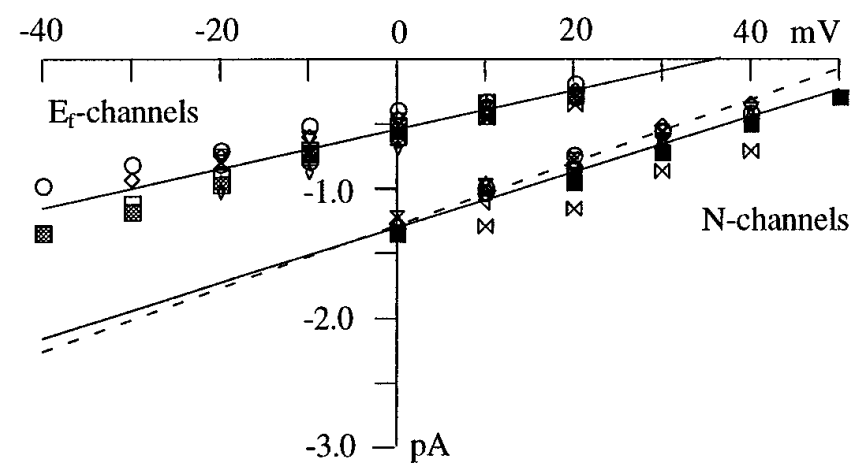

B

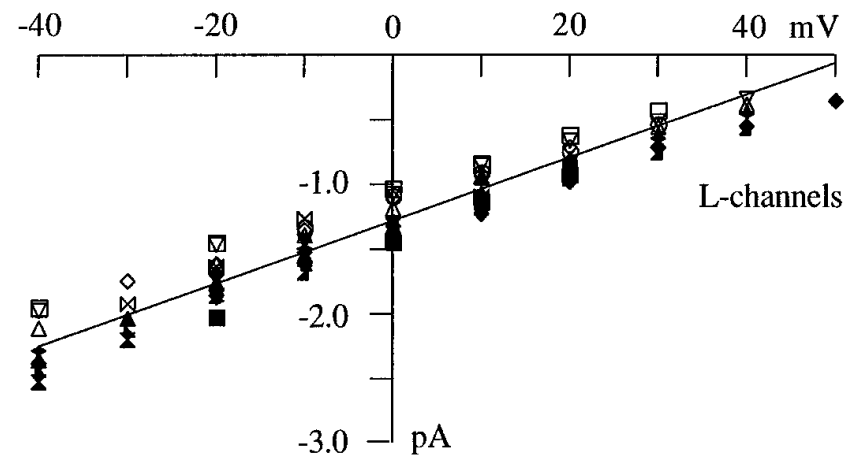

Figure 4. Single-channel $I-V$ relation for N-channels, $\mathrm{E}_{\mathrm{f}}$-channels, and $\mathrm{L}$-channels. $A, \mathrm{~N}$ - and $\mathrm{E}_{\mathrm{f}}$-channel current amplitudes are superimposed to facilitate comparisons. Activity was measured using low-variance-mean histograms during voltage steps ranging from 0 to $+50 \mathrm{mV}$ for $\mathrm{N}$-channels $(n=9)$ and -40 to $+20 \mathrm{mV}$ for $\mathrm{E}_{\mathrm{f}}$-channels $(n=12)$. None of the $\mathrm{N}$-channels were exposed to $\omega \mathrm{CGVIA}$. The lines are linear regression fits to all points from 0 to $+40 \mathrm{mV}$ for $\mathrm{N}$-channels and -40 to $0 \mathrm{mV}$ for $\mathrm{E}_{\mathrm{f}}$-channels. The fit to $\mathrm{N}$-channel data gave a slope conductance of $21 \mathrm{pS}$ and $0 \mathrm{mV}$ intercept of $-1.3 \mathrm{pA}$. The $\mathrm{E}_{\mathrm{f}}$-channel data fit gave a $16 \mathrm{pS}$ conductance and a $0 \mathrm{mV}$ intercept of $-0.6 \mathrm{pA}$. The dashed line is the regression fit to single $\mathrm{L}$-channel currents from $B$. It is replotted here to facilitate comparison to $\mathrm{N}$ - and $\mathrm{E}_{\mathrm{f}}$-channels. $B$, Single L-channel current amplitudes were measured during voltage steps ranging from -30 to +50 $\mathrm{mV}$ using low-variance-mean histograms $(n=10)$. The line is a linear regression fit to all points from -20 to $+20 \mathrm{mV}$. The slope conductance was $24 \mathrm{pS}$, and the $0 \mathrm{mV}$ intercept was $-1.3 \mathrm{pA}$.

$-1.0 \mathrm{pA}$ at $+20 \mathrm{mV}$ ) and activated at more hyperpolarized voltages than the $\mathrm{N}$-channel. The block of $\mathrm{N}$-channel activity was reflected in the reduction of the pseudomacroscopic current at $+20 \mathrm{mV}$ (Fig. 5B, filled diamonds). Over this time, the activity of the single L-channel increased, as shown by the pseudomacroscopic current at $0 \mathrm{mV}$ (Fig. 7B, filled diamonds).

Although the reduction in N-channel activity is consistent with channel block by $\omega$ CGVIA, single channels can "drop out" of the patch for unknown reasons. Therefore, I took advantage of the reversibility of $\omega$ CGVIA block of frog N-channels recorded in $\sim 100 \mathrm{~mm} \mathrm{Ba}^{2+}$ (Boland et al., 1994; Elmslie et al., 1994). For these experiments, the electrode tip was filled with the pipette solution containing $100 \mu \mathrm{M} \omega$ CGVIA and the electrode backfilled with toxin-free solution. Figure $6 A$ shows the increase in $\mathrm{N}$-channel activity over time for one experiment. In four patches treated this way, channel activity increased over time and in each case the recovered channel showed N-channel properties (Fig. $6 B$ ). Thus, the $\mathrm{N}$-channel appears to recover from block as $\omega$ CGVIA diffuses away from the patch. Two of these patches also contained $\mathrm{E}_{\mathrm{f}}$-channel channels, but no L-channel activity was observed in any of the four patches. In three additional patches, no channel activity could be observed up to $1.75 \mathrm{hr}$ after removal of the bubble separating the two solutions in the pipette.

The single-channel $I-V$ for all $\omega$ CGVIA-sensitive channels $(n=$ 9 ) is plotted in Figure $6 C$. The regression fit gives a slope conductance of $20 \mathrm{pS}$ and a single-channel current at $0 \mathrm{mV}$ of -1.29 $\mathrm{pA}$. The pseudomacroscopic ramp current was examined in six $\omega$ CGVIA patches and showed activation near $+10 \mathrm{mV}$ with a mean peak current at $+38 \mathrm{mV}$ (range +31 to $+44 \mathrm{mV}$ ). Although simultaneous $\mathrm{N}$-channel openings were rarely observed in these $\omega$ CGVIA experiments, the presence of the blocker prevented me from determining the number of $\mathrm{N}$-channels present in each patch. The properties of the $\omega$ CGVIA-sensitive channels match those of the putative $\mathrm{N}$-channels identified by activation voltage and the absence of long tail openings in Bay K 8644. Table 2 shows the good agreement between the properties of the macroscopic N-current recorded in $90-100 \mathrm{~mm} \mathrm{Ba}^{2+}$ and the single $\mathrm{N}$-channel presented here.

\section{L-channels}

$\omega$ CGVIA $(100 \mu \mathrm{M})$ was specific for N-channels because L- channels were not blocked. L-channel activity was observed in four patches where the tip of the pipette was filled with toxin-free pipette solution and where the pipette was back-filled with pipette solution containing $100 \mu \mathrm{M} \omega \mathrm{CGVIA}$. The example channel shown in Figure $7 A$ had a $23 \mathrm{pS}$ conductance and a single-channel current at $0 \mathrm{mV}$ of $-1.4 \mathrm{pA}$. Although the pseudomacroscopic current showed a slight decrease over time, channel activity was still high even after $60 \mathrm{~min}$ (Fig. $7 A$ ). In the other patches, L-channel activity increased in one patch, decreased slightly in another, and varied around a central point (approximately -1.4 pA) in the third patch (Fig. 7B).

\section{Channels recorded in the presence of $\omega$ CGVIA}

$\mathrm{E}_{\mathrm{f}}$-channel activity was observed in six $\omega$ CGVIA-diffusion patches at times when N-channel activity in the patch was blocked. However, only one patch was held at $-80 \mathrm{mV}$ for as long as $60 \mathrm{~min}$ (channel illustrated in Fig. 3). Although this patch did not show a decrease in activity, a single observation does not adequately support the conclusion that $\mathrm{E}_{\mathrm{f}}$-channels are not $\omega$ CGVIA-sensitive. Therefore, an additional set of recordings was made with the entire pipette filled with solution containing $100 \mu \mathrm{M} \omega \mathrm{CGVIA}$. Under this condition, $\mathrm{E}_{\mathrm{f}}$-channels were encountered in $\sim 25 \%$ of the patches, which is similar to the frequency in the other experimental conditions (Table 1). As expected, L-channels were not also blocked because the frequency of L-channels patches remained at $25 \%$ in $\omega$ CGVIA (Table 1). However, the constant presence of $\omega$ CGVIA in the pipette reduced frequency of $\mathrm{N}$-channel patches to $\sim 5 \%$ compared with $\sim 43 \%$ in both control and $\omega$ CGVIA-diffusion experiments (Table 1). Not surprisingly, the frequency of patches with no channel activity was nearly doubled by constant exposure to $\omega$ CGVIA. These results are consistent with the conclusion that $\omega$ CGVIA blocks the $20 \mathrm{pS}$ $\mathrm{N}$-channel but that $\mathrm{E}_{\mathrm{f}}$-channels and L-channels are not affected.

Activity of N-like channels was not blocked in two patches tested with $\omega$ CGVIA. In one patch in which the pipette had been backedfilled with $\omega$ CGVIA, channel activity was not altered during the 50 min recording time (Fig. 5B). This channel had a low $P_{\mathrm{o}}$ that was manifested in the small amplitude of the pseudomacroscopic currents (Fig. 5B). In a second patch, N-like channel activity was observed in the constant presence of $\omega$ CGVIA. The slope 
A

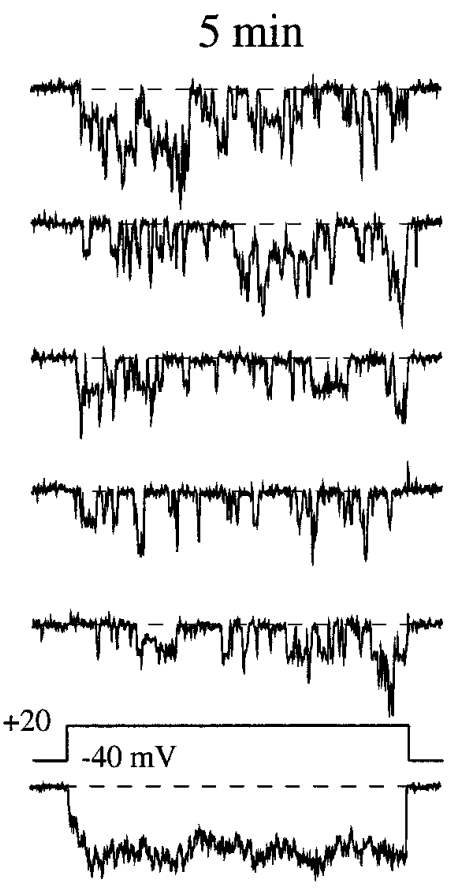

B

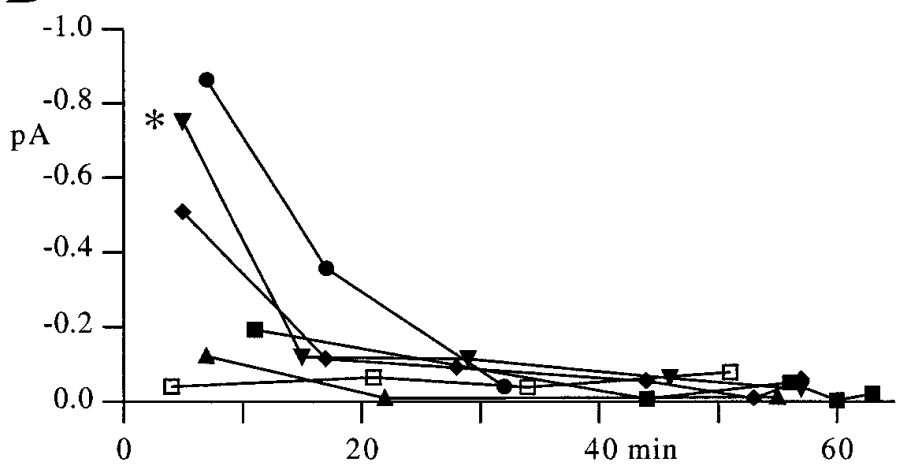

$29 \min$
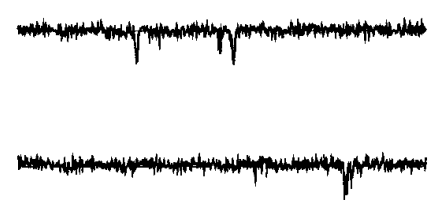

$57 \mathrm{~min}$
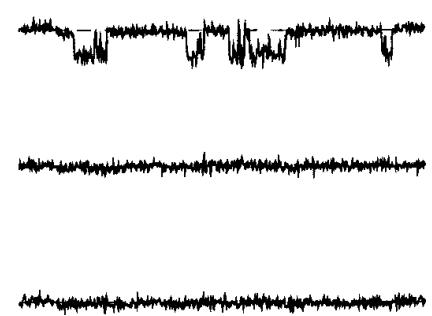
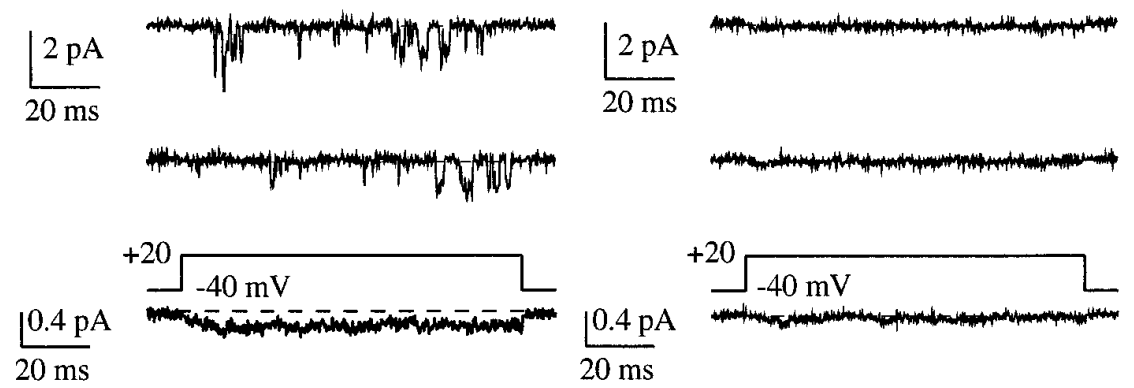

C

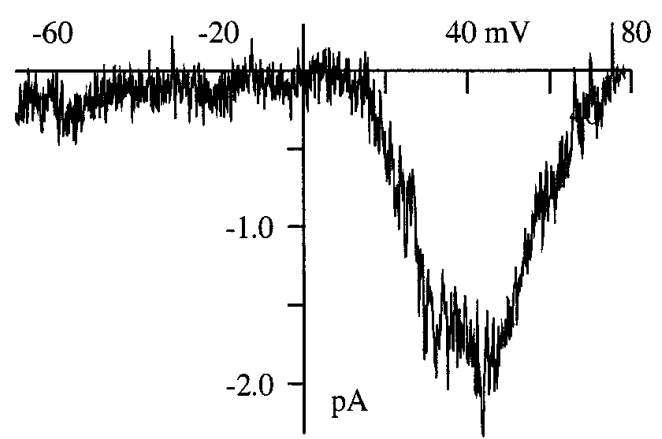

Figure 5. Diffusion of $100 \mu \mathrm{M} \omega \mathrm{CGVIA}$ to the patch blocks single N-channels. $A$, Single-channel sweeps and pseudomacroscopic currents are shown for three time points. Time was measured from the point that the toxin-free tip solution and the $\omega$ CGVIA back-filling solution are allowed to mix. The pseudomacroscopic currents are averages of 46 sweeps for $5 \mathrm{~min}, 90$ sweeps for $29 \mathrm{~min}$, and 39 sweeps for 57 min. This patch contained at least three $\mathrm{N}$-channels and an $\mathrm{E}_{\mathrm{f}}$-channel. $B$, The time course of $\omega$ CGVIA block measured from pseudomacroscopic currents. The current amplitude was measured as the average between 10 and $100 \mathrm{msec}$ of the $+20 \mathrm{mV}$ step. Each patch is represented by a separate symbol, and the asterisk indicates the patch illustrated in $A$. $C$, Pseudomacroscopic ramp current from the patch illustrated in $A$ is shown for comparison with Figure $1 C$ and whole-cell N-current (Elmslie et al., 1994). The current is an average of 15 sweeps.

conductance for these channels calculated over four voltages (range +10 to $+40 \mathrm{mV}$ ) was $19 \mathrm{pS}$, and the single-channel current at $+20 \mathrm{mV}$ was $-0.95 \mathrm{pA}$ (data not shown). The $I-V$ relation measured from voltage ramps showed activation near $+10 \mathrm{mV}$ and peak near $+40 \mathrm{mV}$. These channels may be responsible for the small $\omega$ CGVIA-insensitive whole-cell calcium current that shares several N-current properties such as voltage-dependent inhibition by norepinephrine (Elmslie et al., 1992).

\section{DISCUSSION}

\section{The $\omega$ CGVIA-sensitive $\mathrm{N}$-channel in frog sympathetic neurons}

The identification of single $\mathrm{N}$-channels has been controversial (Elmslie et al., 1994). Putative N-channels have widely variable conductances and current amplitudes (Table 3). The strategy here is to use two fundamental criteria for identification of true
N-channels: (1) the pseudomacroscopic $I-V$ relation should agree with the whole-cell $\omega$ CGVIA-sensitive current recorded in isotonic $\mathrm{Ba}^{+2}$, and (2) the true $\mathrm{N}$-channel should be reversibly blocked by $\omega$ CGVIA (for frog in high $\mathrm{Ba}^{+2}$ ). N-channel activity was characterized in complete isolation from other channels in 17 different patches. The $\mathrm{N}$-channel identified here fits the properties expected from whole-cell $\mathrm{N}$-current recorded in $100 \mathrm{mM} \mathrm{Ba}^{2+}$ (Table 2). N-channels activated near $+10 \mathrm{mV}$ and were available from a holding potential of $-40 \mathrm{mV}$. Peak pseudomacroscopic current was measured at voltages ranging from 28 to $44 \mathrm{mV}$, which is similar to $\mathrm{N}$-current in isotonic $\mathrm{Ba}^{2+}$. The time course of activation was monophasic, as expected for N-current in the absence of modulation by activated G-proteins, and deactivation was rapid after repolarization to $-40 \mathrm{mV}$. N-channel inactivation was incomplete over $100 \mathrm{msec}$ at voltages that generated peak inward current (i.e., $+40 \mathrm{mV}$ ). This fits very well with whole-cell $\mathrm{N}$-current data (Jones and 
A

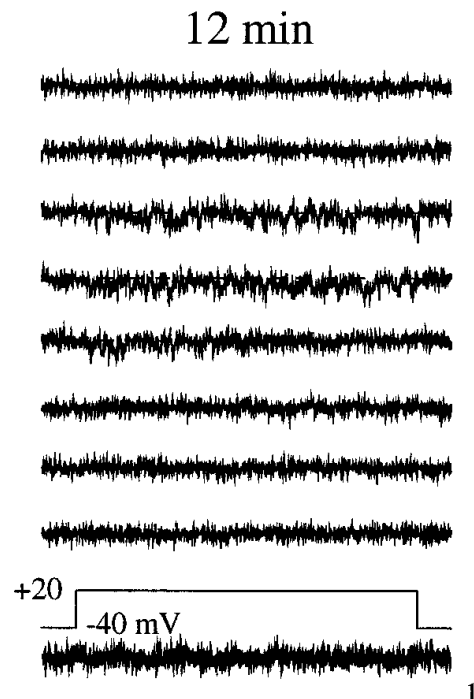

B

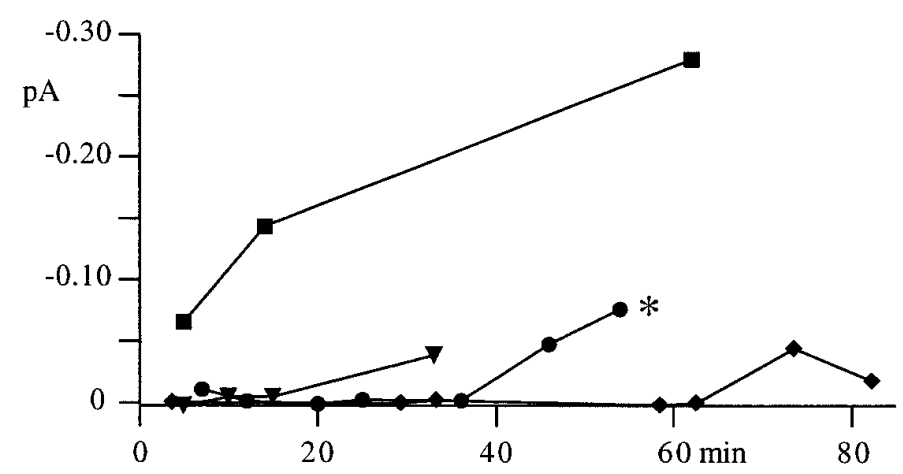

$25 \min$

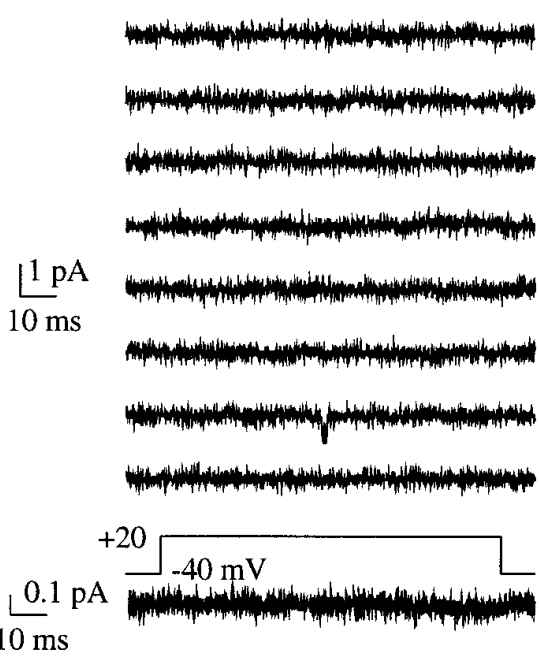

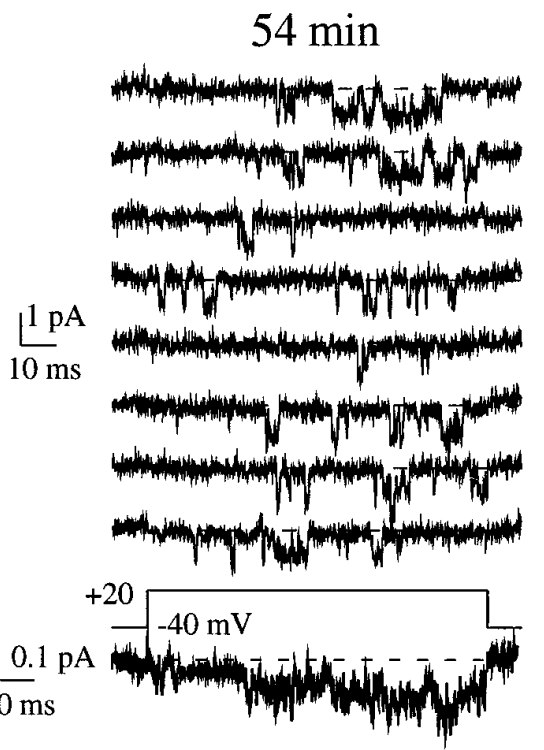

$\mathrm{C}$

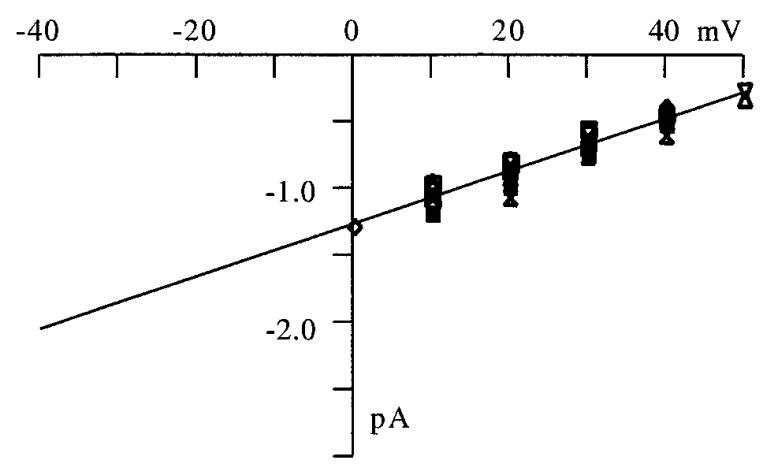

Figure 6. Single N-channels recover from $\omega$ CGVIA block. $A$, Single-channel sweeps and pseudomacroscopic currents are shown for three time points. The clock started when the $\omega$ CGVIA solution in the electrode tip and the toxin-free back-filling solution were allowed to mix. The pseudomacroscopic currents are averages of 100 sweeps for $12 \mathrm{~min}, 100$ sweeps for $25 \mathrm{~min}$, and 22 sweeps for $54 \mathrm{~min}$. Note the channel with a smaller single-channel current in the sweeps recorded at $12 \mathrm{~min}$. This was a $\mathrm{E}_{\mathrm{f}}$-channel that briefly recovered from inactivation. This patch contained at least two $\mathrm{N}$-channels. $B$, The time course of the recovery from $\omega$ CGVIA block measured from pseudomacroscopic currents. The currents were measured as the average between 10 and $100 \mathrm{msec}$ of the $+20 \mathrm{mV}$ step. Each patch is represented by a separate symbol, and the asterisk indicates the patch illustrated in $A$. $C$, The single-channel $I-V$ relation for $\omega$ CGVIA-sensitive N-channels. This plot includes channels that were blocked during the diffusion of $\omega$ CGVIA to the patch (Fig. $5 ; n=5$ ) and channels that recovered during diffusion of $\omega$ CGVIA from the patch $(n=4)$. The line is a linear regression fit to all of the points from 0 to $+40 \mathrm{mV}$. The slope conductance was $20 \mathrm{pS}$, and the $0 \mathrm{mV}$ intercept was $-1.3 \mathrm{pA}$.

Table 2. A comparison of the properties of macroscopic calcium currents and single calcium channels

\begin{tabular}{|c|c|c|c|c|c|c|}
\hline Current Property & N-current & N-channel & L-current & L-channel & $E_{f}$-current & $\mathrm{E}_{\mathrm{f}}$-channel \\
\hline Slope $\gamma$ & NA & $20 \mathrm{pS}$ & NA & $24 \mathrm{pS}$ & $\mathrm{Na}$ & 13-20 PS \\
\hline$i$ at $0 \mathrm{mV}$ & NA & $-1.3 \mathrm{pA}$ & NA & $-1.3 \mathrm{pA}$ & NA & $-0.6 \mathrm{pA}$ \\
\hline Activation voltage & $+10 \mathrm{mV}$ & $+10 \mathrm{mV}$ & $-20 \mathrm{mV}$ & $-20 \mathrm{mV}$ & $-30 \mathrm{mV}$ & $-30 \mathrm{mV}$ \\
\hline Inactivation at $-40 \mathrm{mV}$ & Weak & Weak & Weak & Weak & Strong & Strong \\
\hline DHP sensitivity & No & No & Yes & Yes & No & No \\
\hline$\omega$ CGVIA block & Yes & Yes & No & No & No & No \\
\hline
\end{tabular}

NA, not available. Macroscopic current data from Elmslie et al., 1994. $\mathrm{E}_{\mathrm{f}}$-channel data from Elmslie et al., 1994 and this paper. Recorded in $\sim 100 \mathrm{mM} \mathrm{Ba}^{2+}$ from frog sympathetic neurons.

Marks, 1989; Werz et al., 1993). N-channels were reversibly blocked by $100 \mu \mathrm{M} \omega \mathrm{CGVIA}$ with a time course that is consistent with whole-cell data in isotonic $\mathrm{Ba}^{2+}$ (Boland et al., 1994; Elmslie et al., 1994). However, L- and $\mathrm{E}_{\mathrm{f}}$-channels were not affected. The evidence supports the conclusion that this $20 \mathrm{pS}$ channel underlies the $\omega$ CGVIA-sensitive N-type calcium current in frog sympathetic neurons.

Two patches contained channels that fit the voltagedependent properties of the N-channel, but they were not blocked by $\omega$ CGVIA. Whole-cell recordings have demon- 
A

$10 \min$

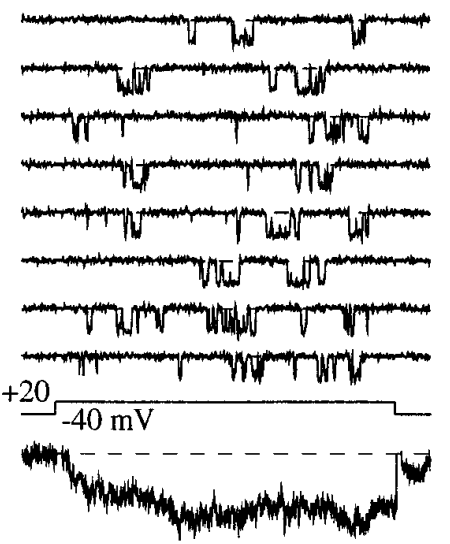

$47 \mathrm{~min}$

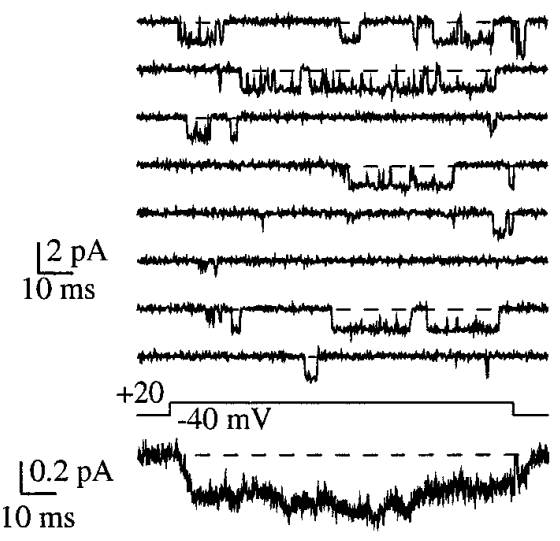

$62 \min$

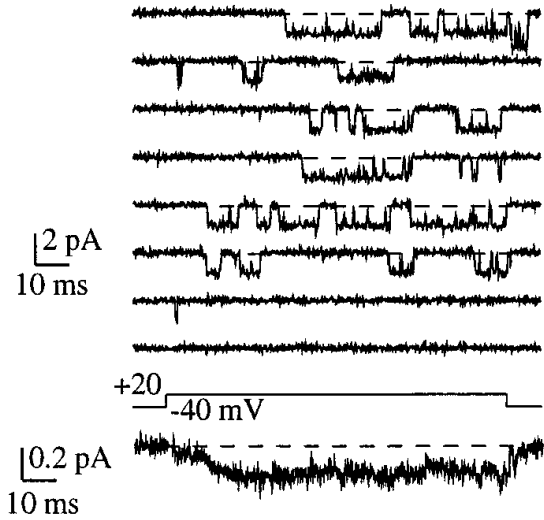

B

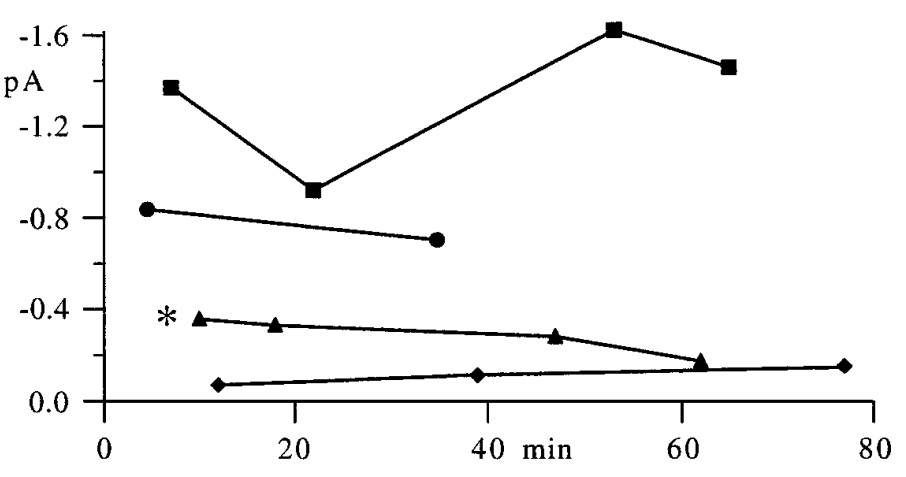

$\mathrm{C}$

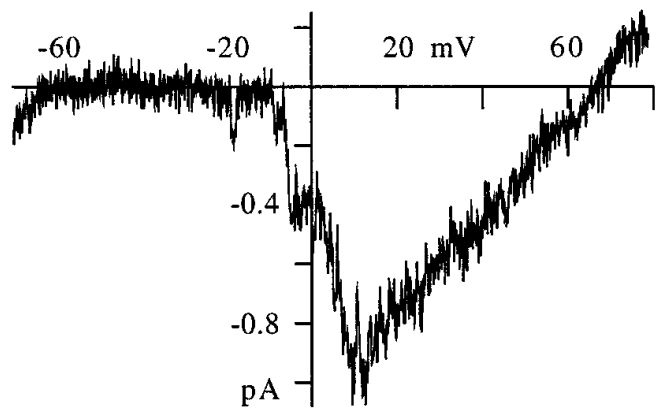

Figure 7. L-channels were not blocked by $\omega$ CGVIA. $A$, L-channel activity is shown for three time points after allowing the front- and $\omega$ CGVIAcontaining back-filling solutions to mix. This patch appeared to contain a single L-channel. $B$, Current amplitudes were measured from pseudomacroscopic currents as an average from 10 to $100 \mathrm{msec}$ during the voltage step. For each L-channel patch, $100 \mu \mathrm{M} \omega \mathrm{CGVIA}$ was in the back-filling solution while the tip was filled with toxin-free pipette solution. Each patch $(n=4)$ is represented by a different symbol, and the asterisk indicates the patch shown in $A$. $C$, Pseudomacroscopic ramp current is shown from the patch illustrated in $A$ as an average of 15 sweeps.

\begin{tabular}{|c|c|c|c|c|c|c|c|}
\hline Channel properties & $\begin{array}{l}\text { Chick DRG } \\
\text { neurons }{ }^{1}\end{array}$ & $\begin{array}{l}\text { Rat CA3 } \\
\text { neurons }\end{array}$ & $\begin{array}{l}\text { Rat } \\
\text { motoneuron }^{3}\end{array}$ & $\begin{array}{l}\text { Rat } \\
\text { sympathetic }^{4}\end{array}$ & $\begin{array}{l}\text { Neurohypophysis } \\
\text { terminals }\end{array}$ & $\begin{array}{l}\text { Rat } \\
\text { sympathetic }^{6}\end{array}$ & $\begin{array}{l}\text { Frog } \\
\text { sympathetic }^{7}\end{array}$ \\
\hline Slope $\gamma$ & $13 \mathrm{pS}$ & $12 \mathrm{pS}$ & $14 \mathrm{pS}$ & $11 \mathrm{pS}$ & $10-15 \mathrm{pS}$ & $17-22 \mathrm{pS}$ & $20 \mathrm{pS}$ \\
\hline i at $0 \mathrm{mV}$ & $-1 \mathrm{pA}$ & $-0.5 \mathrm{pA}$ & $-0.7 \mathrm{pA}$ & $-0.8 \mathrm{pA}$ & NR & $-1.5 \mathrm{pA}$ & $-1.3 \mathrm{pA}$ \\
\hline Activation voltage & $-20 \mathrm{mV}$ & $-30 \mathrm{mV}$ & $-10 \mathrm{mV}$ & $-30 \mathrm{mV}$ & $10 \mathrm{mV}$ & $10 \mathrm{mV}$ & $10 \mathrm{mV}$ \\
\hline Inactivation at $-40 \mathrm{mV}$ & Strong & Strong & Strong & Strong & Strong & Moderate & Weak \\
\hline$\omega$ CGVIA sensitivity & NT & NT & NT & NT & NT & YES? & YES \\
\hline
\end{tabular}

NT, not tested; NR, not reported

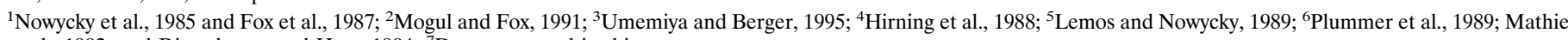
et al., 1992, and Rittenhouse and Hess, 1994; ${ }^{7}$ Data presented in this paper.

YES? refers to unpublished data of N-channel block by $\omega$ CGVIA (see Discussion, Plummer et al., 1989).

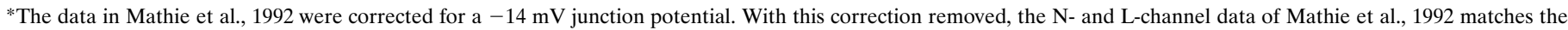
data presented in Plummer et al., 1989; Rittenhouse and Hess, 1994; and this paper.

strated an $\omega$ CGVIA- and DHP-insensitive calcium current with properties similar to those of the N-current. These similarities include voltage-dependent inhibition by norepinephrine (Elmslie et al., 1992) and an enhancement of inactivation rate by the phosphatase inhibitor okadaic acid (Werz et al., 1993). This calcium current comprises $\leq 5 \%$ of the whole-cell calcium current in $2 \mathrm{mM} \mathrm{Ba}^{2+}$, so the frequency of recording this channel type should be low.

\section{Putative N-channels from other neuronal preparations}

Calcium channels in several different preparations have been identified as "N-type" based on DHP insensitivity and strong inactivation at a holding potential of $-40 \mathrm{mV}$ (Table 3 , columns 1-4). However, DHP insensitivity is a characteristic of many calcium channels, and $\mathrm{N}$-current in isotonic $\mathrm{Ba}^{2+}$ does not inactivate strongly at a holding potential of $-40 \mathrm{mV}$. These putative 
$\mathrm{N}$-channels activated at voltages hyperpolarized to $\mathrm{N}$-current in isotonic $\mathrm{Ba}^{2+}$, and their single-channel current was smaller than that of the frog $\mathrm{N}$-channel. Thus, the properties of these channels do not match those expected for $\mathrm{N}$-current.

The putative $\mathrm{N}$-channel recorded from rat neurohypophysis terminals activated at voltages close to that of $\mathrm{N}$-current in isotonic $\mathrm{Ba}^{2+}$ (Table 3 ) but had a smaller conductance $(10-15 \mathrm{pS}$ ) than the frog $\mathrm{N}$-channel and inactivated strongly at $-30 \mathrm{mV}$ (Lemos and Nowycky, 1989). Fujita et al. (1993) observed a 14 pS channel for B-class mRNA (N-channel) expressed in dysgenic mouse skeletal muscle that activated at voltages greater than or equal to $-10 \mathrm{mV}$. It will be interesting to see whether future experiments demonstrate that native $\mathrm{N}$-channels can exhibit a broad range of conductances. $\omega$ CGVIA block of a $13 \mathrm{pS}$ calcium channel recorded from chick sensory neurons has been reported (Aosaki and Kasai, 1989). However, there are problems equating this " $\omega$ CGVIA-sensitive" channel with the N-current. The singlechannel activity inactivated more rapidly during voltage steps than whole-cell $\mathrm{N}$-current, and the channels activated near $-20 \mathrm{mV}$ in isotonic $\mathrm{Ba}^{2+}$ (Aosaki and Kasai, 1989). The loss of channel activity observed in the $\omega$ CGVIA blocking experiments could have been caused by rundown because the channels were recorded in the outside-out configuration.

Many properties of the putative $\mathrm{N}$-channel in rat sympathetic neurons match those of the frog $\mathrm{N}$-channels (Table 3 ). One difference is that the rat $\mathrm{N}$-channel exhibited moderate inactivation at $-30 \mathrm{mV}(\sim 50 \%)$ (Plummer et al., 1989). This inactivation is larger than expected for N-current in frog sympathetic neurons but is similar to a DHP- and $\omega$ CGVIA-resistant calcium current recorded in rat sympathetic neurons exposed to isotonic $\mathrm{Ba}^{2+}$ $(\sim 35 \%$ at $-40 \mathrm{mV})$ (Boland et al., 1994). Furthermore, the calcium current recorded by Boland et al. (1994) activated near $-10 \mathrm{mV}$, which is close to the $\mathrm{N}$-channel activation voltage. Plummer et al. (1989) reported in their Discussion that their rat $\mathrm{N}$-channel was blocked by $\omega$ CGVIA, but the data were not shown. Mathie et al. (1992) reported a 17 pS N-channel in rat sympathetic neurons that was blocked by including $\omega$ CGVIA in the pipette solution (data not shown). The properties of the $17 \mathrm{pS}$ N-channel match those of the frog $\mathrm{N}$-channel after allowing for a $14 \mathrm{mV}$ correction for junction potential used by Mathie et al. (1992). The putative rat $\mathrm{N}$-channel has been shown to gate in three modes that were defined by open probability (Rittenhouse and Hess, 1994). As stated above, I have not noticed different gating modes in the frog N-channel experiments. However, it is nearly impossible to discern modes in multichannnel patches like those usually recorded here (only 2 single-channel patches).

The N-channel recorded from neuroblastoma IMR32 cells by Carabelli et al. (1996) nicely matches the frog N-channel characterized here. The slope conductance of the IMR32 N-channel was $19 \mathrm{pS}$, and the single-channel current at $+20 \mathrm{mV}$ was $0.9 \mathrm{pA}$ (compared with $0.87 \mathrm{pA}$ for the frog $\mathrm{N}$-channel). The IMR32 $\mathrm{N}$-channel activated near $0 \mathrm{mV}$, which is $\sim 10 \mathrm{mV}$ hyperpolarized to the frog N-channel.

\section{L-channels}

L-type calcium channels were identified by long tail openings and activation near $-20 \mathrm{mV}$ with $1 \mu \mathrm{M}$ Bay K 8644 present in the bath. Consistent with this identification, these channels were not blocked by $100 \mu \mathrm{M} \omega \mathrm{CGVIA}$. Thus, pharmacology provides an excellent means by which to separate N-channels from L-channels (Plummer et al., 1989), but slope conductance and current amplitude were too similar to be a reliable criteria for separation (Fig.
4). In addition, one must be careful when using $P_{\mathrm{o}}$ as a criterion because both $\mathrm{N}$ - and L-channels are open much of the time at depolarized potentials (greater than or equal to $+30 \mathrm{mV}$ ). L-channels were found in 10 of 43 patches, which is surprisingly frequent because only $\sim 5 \%$ of the whole-cell current is sensitive to DHP antagonists (Jones and Jacobs, 1990; Elmslie et al., 1992). However, L-channel density appeared to be lower than either Nor $\mathrm{E}_{\mathrm{f}}$-channels because there was a larger fraction of single L-channel patches (7/17).

\section{$E_{f}$-channels}

The $E_{f}$ /novel calcium channel was identified in an earlier paper (Elmslie et al., 1994). The name novel was used because the whole-cell current had not been recognized previously. Recent experiments demonstrate that "novel" channels are likely to be expressed from E-class mRNA (Lewis et al., 1995). First, PCR was used to demonstrate that frog sympathetic neurons express E-class mRNA. Second, "novel" channel properties closely match those of the channel expressed by E-class mRNA transfected into HEK 293 cells (Lewis et al., 1995). The "novel" channel is tentatively referred to here as $\mathrm{E}_{\mathrm{f}}$ to facilitate discussion, but a solid identification will require further study.

$\mathrm{E}_{\mathrm{f}}$-channels could be separated from $\mathrm{N}$ - and L-channels by strong inactivation at $-40 \mathrm{mV}$ and the small single-channel current amplitude. As seen above, slope conductance was not a good method by which to separate $E_{f}$-channels from the others. The slope conductance for $\mathrm{E}_{\mathrm{f}}$-channels ranged from 13 to $19 \mathrm{pS}$, which overlaps the range observed for $\mathrm{N}$ - and L-channels. Previous measurements of slope conductance for channels gating in this voltage range varied from 15 to 19 pS (Lipscombe et al., 1988, 1989; Delcour et al., 1993; Elmslie et al., 1994). Some of this variability could be caused by different modes of $E_{f}$-channel gating as described previously (Delcour et al., 1993). I have made no effort to distinguish modes because no single- $\mathrm{E}_{\mathrm{f}}$-channel patches were recorded. As demonstrated for whole-cell $E_{f}$ current, $\mathrm{E}_{\mathrm{f}}$-channels were not blocked by $\omega$ CGVIA. $\mathrm{E}_{\mathrm{f}}$-channel activity was observed in $\omega$ CGVIA diffusion experiments when the $\mathrm{N}$-channel activity in the same patch was blocked $(n=6)$. In addition, $\mathrm{E}_{\mathrm{f}}$-channel activity was observed in the constant presence of $\omega$ CGVIA $(n=5)$.

The $\mathrm{E}_{\mathrm{f}}$-channel is primarily inactivated at a holding potential of $-40 \mathrm{mV}$ but not completely. Whole-cell recordings show that $\mathrm{E}_{\mathrm{f}}$-current is reduced by $\sim 80 \%$ when the holding potential is depolarized from -80 to $-40 \mathrm{mV}$. Single-channel recordings demonstrate that $E_{\mathrm{f}}$-channels could recover from inactivation during a constant holding potential of $-40 \mathrm{mV}$. Once recovered, the channel could dwell in the activatable state for many seconds. This can be seen in Figure $6 A(12 \mathrm{~min})$, in which the $\mathrm{E}_{\mathrm{f}}$-channel was active over three consecutive sweeps that spanned $6 \mathrm{sec}$.

\section{Summary and conclusion}

There are currently three mRNAs that can be expressed to form DHP-insensitive calcium channels. In addition, isoforms of channel-associated proteins have been cloned. Given this diversity, it is imperative that single calcium channels be identified as rigorously as possible. In this paper, I identify $\mathrm{N}$-type, L-type, and $\mathrm{E}_{\mathrm{f}}$-type calcium channels by comparing their biophysical and pharmacological properties with those of the whole-cell currents recorded in isotonic $\mathrm{Ba}^{+2}$. The frog $\mathrm{N}$-channel identified here is similar to $\mathrm{N}$-channels recorded from rat sympathetic neurons (Plummer et al., 1989; Mathie et al., 1992; Rittenhouse and Hess, 1994) and from human neuroblastoma IMR32 cells (Carabelli et 
al., 1996). We currently do not have sufficient information to determine whether putative $\mathrm{N}$-channels from different preparations are indeed $\omega$ CGVIA-sensitive N-channels.

\section{REFERENCES}

Aosaki T, Kasai H (1989) Characterization of two kinds of high-voltageactivated Ca-channel currents in chick sensory neurons. Differential sensitivity to dihydropyridines and $\omega$-conotoxin GVIA. Pflügers Arch 414:150-156.

Boland LM, Morrill JA, Bean BP (1994) $\omega$-Conotoxin block of N-type calcium channels in frog and rat sympathetic neurons. J Neurosci 14:5011-5027.

Carabelli V, Lovallo M, Magnelli V, Zucker H, Carbone E (1996) Voltage-dependent modulation of single N-type $\mathrm{Ca}^{2+}$ channel kinetics by receptor agonists in IMR32 cells. Biophys J 70:2144-2154.

Delcour AH, Tsien RW (1993) Altered prevalence of gating modes in neurotransmitter inhibition of N-type calcium channels. Science 259:980-984.

Delcour AH, Lipscombe D, Tsien RW (1993) Multiple modes of N-type calcium channel activity distinguished by differences in gating kinetics. J Neurosci 13:181-194.

Elmslie KS (1992) Calcium current modulation in frog sympathetic neurones: multiple neurotransmitters and G proteins. J Physiol (Lond) 451:229-246.

Elmslie KS, Kammermeier PJ, Jones SW (1992) Calcium current modulation in frog sympathetic neurones: L-current is relatively insensitive to neurotransmitters. J Physiol (Lond) 456:107-123.

Elmslie KS, Kammermeier PJ, Jones SW (1994) Reevaluation of $\mathrm{Ca}^{2+}$ channel types and their modulation in bullfrog sympathetic neurons. Neuron 13:217-228.

Forti L, Pietrobon D (1993) Functional diversity of L-type calcium channels in rat cerebellar neurons. Neuron 10:437-450.

Fox AP, Nowycky MC, Tsien RW (1987) Single-channel recordings of three types of calcium channels in chick sensory neurones. J Physiol (Lond) 394:173-200.

Fujita Y, Mynlieff M, Dirksen RT, Kim M-S, Niidome T, Nakai J, Friedrich T, Iwabe N, Miyata T, Furuichi T, Furutama D, Mikoshiba K, Mori Y, Beam KG (1993) Primary structure and functional expression of the $\omega$-conotoxin-sensitive $\mathrm{N}$-type calcium channel from rabbit brain. Neuron 10:585-598.

Hirning LD, Fox AP, McCleskey EW, Olivera BM, Thayer SA, Miller RJ, Tsien RW (1988) Dominant role of N-type $\mathrm{Ca}^{2+}$ channels in evoked release of norepinephrine from sympathetic neurons. Science 239:57-61.

Horn R, Marty A (1988) Muscarinic activation of ionic currents measured by a new whole-cell recording method. J Gen Physiol 92:145-159.

Jones SW (1987) Sodium currents in dissociated bullfrog sympathetic neurones. J Physiol (Lond) 389:605-627.
Jones SW, Jacobs LS (1990) Dihydropyridine actions on calcium currents of frog sympathetic neurons. J Neurosci 10:2261-2267.

Jones SW, Marks TN (1989) Calcium currents in bullfrog sympathetic neurons. II. Inactivation. J Gen Physiol 94:169-182.

Kavalali ET, Plummer MR (1994) Selective potentiation of a novel calcium channel in rat hippocampal neurones. J Physiol (Lond) 480:475-484.

Kuffler SW, Sejnowski TJ (1983) Peptidergic and muscarinic excitation at amphibian sympathetic synapses. J Physiol (Lond) 341:257-278.

Lemos JR, Nowycky MC (1989) Two types of calcium channels coexist in peptide-releasing vertebrate nerve terminals. Neuron 2:1419-1426.

Lewis BA, Dubel S, Soong TW, Snutch TP, Yue DT (1995) Elementary properties of two non-L-type $\mathrm{Ca}^{2+}$ channels in frog sympathetic neurons. Biophys J (Abstr) 68:A361.

Lipscombe D, Madison DV, Poenie M Reuter H, Tsien RY, Tsien RW (1988) Spatial distribution of calcium channels and cytosolic calcium transients in growth cones and cell bodies of sympathetic neurons. Proc Natl Acad Sci USA 85:2398-2402.

Lipscombe D, Kongsamut S, Tsien RW (1989) $\alpha$-Adrenergic inhibition of sympathetic neurotransmitter release mediated by modulation of N-type calcium-channel gating. Nature 340:639-642.

Mathie A, Bernheim L, Hille B (1992) Inhibition of N- and L-type calcium channels by muscarinic receptor activation in rat sympathetic neurons. Neuron 8:907-914.

Mogul DJ, Fox AP (1991) Evidence for multiple type of $\mathrm{Ca}^{2+}$ channels in acutely isolated hippocampal CA3 neurones of the Guinea-Pig. J Physiol (Lond) 433:259-281.

Nowycky MC, Fox AP, Tsien RW (1985) Three types of neuronal calcium channel with different calcium agonist sensitivity. Nature 316:440-443.

Patlak JB (1988) Sodium channel subconductance levels measured with a new variance-mean analysis. J Gen Physiol 92:413-430.

Patlak JB (1993) Measuring kinetics of complex single ion channel data using mean-variance histograms. Biophys J 65:29-42.

Plummer MR, Logothetis DE, Hess P (1989) Elementary properties and pharmacological sensitivities of calcium channels in mammalian peripheral neurons. Neuron 2:1453-1463.

Rittenhouse AR, Hess P (1994) Microscopic heterogeneity in unitary $\mathrm{N}$-type calcium currents in rat sympathetic neurons. J Physiol (Lond) 474:87-99.

Umemiya M, Berger AJ (1995) Single-channel properties of four calcium channels types in rat motoneurons. J Neurosci 15:2218-2224.

Werz MA, Elmslie KS, Jones SW (1993) Phosphorylation enhances inactivation of N-type calcium channels. Pflügers Arch 424:538-545.

Zhou W, Jones SW (1995) Surface charge and calcium channel saturation in bullfrog sympathetic neurons. J Gen Physiol 105:441-462. 